\title{
Estimating postoperative left ventricular volume: Identification of responders to surgical ventricular reconstruction
}

\author{
Satoru Wakasa, MD, PhD, ${ }^{\mathrm{a}}$ Yoshiro Matsui, MD, $\mathrm{PhD},{ }^{\mathrm{a}}$ Junjiro Kobayashi, $\mathrm{MD}, \mathrm{PhD},{ }^{\mathrm{b}}$ \\ Yasunori Cho, $\mathrm{MD}, \mathrm{PhD},{ }^{\mathrm{c}}$ Hitoshi Yaku, MD, $\mathrm{PhD},{ }^{\mathrm{d}}$ Goro Matsumiya, $\mathrm{MD}, \mathrm{PhD},{ }^{\mathrm{e}}$ \\ Tadashi Isomura, MD, PhD ${ }^{f}$ Shuichiro Takanashi, $\mathrm{MD}, \mathrm{PhD},{ }^{\mathrm{g}}$ Akihiko Usui, $\mathrm{MD}, \mathrm{PhD},{ }^{\mathrm{h}}$ \\ Ryuzo Sakata, MD, PhD, ${ }^{i}$ Tatsuhiko Komiya, MD, PhD ${ }^{j}$ Yoshiki Sawa, MD, PhD, ${ }^{k}$ \\ Yoshikatsu Saiki, MD, PhD, ${ }^{1}$ Hideyuki Shimizu, MD, $\mathrm{PhD},{ }^{\mathrm{m}}$ Atsushi Yamaguchi, MD, PhD, \\ Kimikazu Hamano, $\mathrm{MD}, \mathrm{PhD},{ }^{\circ}$ and Hirokuni Arai, $\mathrm{MD}, \mathrm{PhD}^{\mathrm{p}}$
}

\begin{abstract}
Objectives: The postoperative left ventricular end-systolic volume index and ejection fraction are benchmarks of surgical ventricular reconstruction but remain unpredictable. This study aimed to identify who could be associated with a higher long-term survival by adding surgical ventricular reconstruction to coronary artery bypass grafting than coronary artery bypass grafting alone (responders to surgical ventricular reconstruction).

Methods: The subjects were 293 patients (median age, 63 years; 255 men) who underwent coronary artery bypass grafting for ischemic heart disease with left ventricular dysfunction in 16 cardiovascular centers in Japan. The relationships among surgical ventricular reconstruction, postoperative end-systolic volume index, ejection fraction, and survival were analyzed to identify responders to surgical ventricular reconstruction.
\end{abstract}

Results: Surgical ventricular reconstruction was performed in 165 patients $(56 \%)$. The end-systolic volume index and ejection fraction significantly improved (end-systolic volume index, 91 to $64 \mathrm{~mL} / \mathrm{m}^{2}$; ejection fraction, $28 \%$ to $35 \%$ ) for all patients. The postoperative end-systolic volume index and ejection fraction were estimated, and surgical ventricular reconstruction was found to be significantly associated with both end-systolic volume index $\left(14.5 \mathrm{~mL} / \mathrm{m}^{2}\right.$ reduction, $P<.001)$ and ejection fraction $(3.1 \%$ increase, $P=.003)$. During the median follow-up of 6.8 years, 69 patients $(24 \%)$ died. Only the postoperative ejection fraction was significantly associated with survival (hazard ratio, $0.925 ; 95 \%$ confidence interval, 0.885-0.968), although this effect was limited to those with postoperative end-systolic volume index of 40 to $80 \mathrm{~mL} / \mathrm{m}^{2}$ in the subgroup analysis (hazard ratio, 0.932; 95\% confidence interval, 0.894-0.973).

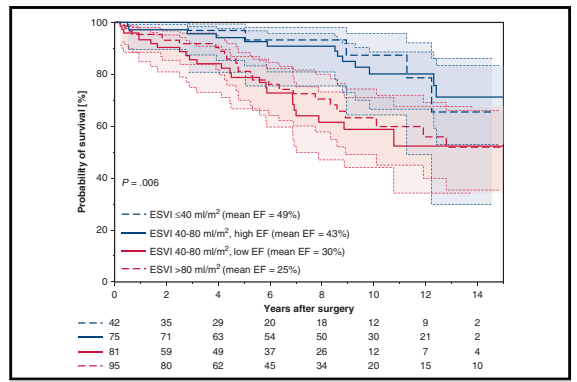

Postoperative ESVI and EF were associated with survival after $C A B G \pm S V R$.

\section{Central Message}

Because SVR could provide survival benefit by improving $\mathrm{EF}$ for those with postoperative ESVI within a specific range, responders to SVR could be identified by estimating postoperative ESVI.

\section{Perspective}

Although postoperative ESVI and EF are benchmarks of SVR, they are unpredictable and vary among patients This makes it difficult to identify who would benefit from SVR. This study elucidated the relationships among SVR, postoperative ESVI, EF, and survival. Our results can help identify who would be associated with a higher survival by adding SVR to CABG compared with CABG alone.

See Editorial Commentary page 2097.
From the ${ }^{\mathrm{a}}$ Department of Cardiovascular and Thoracic Surgery, Hokkaido University Graduate School of Medicine, Sapporo, Japan; ${ }^{b}$ Department of Cardiovascular Surgery, National Cerebral and Cardiovascular Center, Suita, Japan; ${ }^{\mathrm{c} D e p a r t m e n t}$ of Cardiovascular Surgery, Tokai University School of Medicine, Isehara, Japan; ${ }^{\mathrm{d} D e}$ partment of Cardiovascular Surgery, Kyoto Prefectural University of Medicine, Kyoto, Japan; ${ }^{\mathrm{e}}$ Department of Cardiovascular Surgery, Chiba University Graduate School of Medicine, Chiba, Japan; ${ }^{\mathrm{f}}$ Department of Cardiovascular Surgery, Tokyo Heart Center, Tokyo, Japan; ${ }^{\mathrm{g}}$ Department of Cardiovascular Surgery, Sakakibara Heart Institute, Tokyo, Japan; ${ }^{\mathrm{h}}$ Department of Cardiac Surgery, Nagoya University Graduate School of Medicine, Nagoya, Japan; ${ }^{i}$ Department of Cardiovascular Surgery, Kyoto University Graduate School of Medicine, Kyoto, Japan; ${ }^{j}$ Division of Cardiovascular Surgery, Kurashiki Central Hospital, Kurashiki, Japan; ${ }^{\mathrm{k}}$ Department of Cardiovascular Surgery, Osaka University Graduate School of Medicine, Osaka, Japan; ${ }^{\mathrm{I}}$ Division of Cardiovascular Surgery, Tohoku University Graduate School of Medicine, Sendai, Japan; ${ }^{\mathrm{m}}$ Department of Cardiovascular Surgery,
Keio University School of Medicine, Tokyo, Japan; ${ }^{\mathrm{n}}$ Department of Cardiovascular Surgery, Saitama Medical Center, Jichi Medical University, Saitama, Japan; ${ }^{\circ}$ Department of Surgery and Clinical Science, Yamaguchi University Graduate School of Medicine, Ube, Japan; and ${ }^{\mathrm{P}}$ Department of Cardiovascular Surgery, Tokyo Medical and Dental University Graduate School of Medical and Dental Sciences, Tokyo, Japan.

Received for publication Sept 20, 2017; revisions received June 19, 2018; accepted for publication June 25, 2018; available ahead of print Sept 6, 2018.

Address for reprints: Yoshiro Matsui, MD, PhD, Department of Cardiovascular and Thoracic Surgery, Hokkaido University Graduate School of Medicine, Kita-15, Nishi-7, Kita-ku, Sapporo 060-8638, Japan (E-mail: ymatsui@med.hokudai.ac.jp). $0022-5223 / \$ 36.00$

Copyright (C) 2018 by The American Association for Thoracic Surgery https://doi.org/10.1016/j.jtcvs.2018.06.090 

Abbreviations and Acronyms
$\mathrm{CABG}=$ coronary artery bypass grafting
$\mathrm{EF}=$ ejection fraction
ESVI $=$ end-systolic volume index
IQR = interquartile range
$\mathrm{LV}=$ left ventricle
MRI = magnetic resonance imaging
MV = mitral valve
SVR = surgical ventricular reconstruction

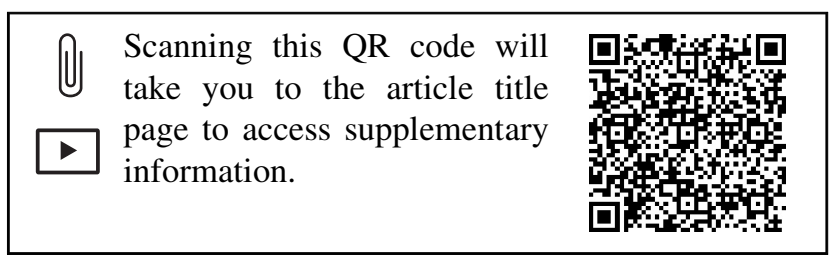

Conclusions: Adding surgical ventricular reconstruction to coronary artery bypass grafting could reduce the mortality risk by increasing ejection fraction for those with a postoperative end-systolic volume index within a specific range. The postoperative end-systolic volume index could demarcate responders to surgical ventricular reconstruction, and its estimation can help in surgical decision making. (J Thorac Cardiovasc Surg 2018;156:2088-96)

The ideal candidate for surgical ventricular reconstruction (SVR) has not been identified because the survival benefit of adding SVR to coronary artery bypass grafting (CABG) for those with ischemic heart disease remains unproven. ${ }^{1}$ Volume reduction of the left ventricle (LV) is one of the goals of SVR because the dilated LV after myocardial infarction predicts mortality. ${ }^{2}$ Postoperative LV end-systolic volume index (ESVI) less than $60 \mathrm{~mL} / \mathrm{m}^{2}$, greater than $30 \%$ ESVI reduction, and greater than $33 \%$ ESVI reduction with a resultant postoperative ESVI less than $90 \mathrm{~mL} / \mathrm{m}^{2}$ are considered to be desired goals of SVR, because these are associated with lower mortality rates after SVR. ${ }^{3-5}$ On the other hand, the postoperative ESVI less than $70 \mathrm{~mL} / \mathrm{m}^{2}$ could demarcate candidates for SVR, because this is associated with a higher survival for those with CABG plus SVR than those with $\mathrm{CABG}$ alone. ${ }^{4}$ However, the volume reduction effect by SVR has limits. The maximum values of preoperative $\mathrm{LV}$ sizes to achieve postoperative ESVI less than $60 \mathrm{~mL} / \mathrm{m}^{2}$ are $65 \mathrm{~mm}$ for $\mathrm{LV}$ end-diastolic diameter and $94 \mathrm{~mL} / \mathrm{m}^{2}$ for $\mathrm{ESVI}^{3}$ On the other hand, because the LV volume reduction by SVR may cause a decrease of stroke volume, ${ }^{6}$ a sufficient LV ejection fraction (EF) should be preserved postoperatively. Otherwise, reduced LV stroke volume results in low output syndrome. ${ }^{7}$ Although SVR was reported to improve EF with a reduction of the LV volume, ${ }^{6,8}$ the postoperative values of such parameters vary depending on each patient's condition. This makes it difficult to identify who would benefit from SVR, because there remains no method to estimate the postoperative ESVI and EF after SVR specifically and individually. Therefore, we hypothesized that elucidation of the specific effects of SVR on ESVI and EF could make it possible to estimate the postoperative ESVI and EF, and this could help identify who would be associated with a higher long-term survival by adding SVR to $\mathrm{CABG}$ than CABG alone (ie, responder to SVR). Thus, this study aimed to identify the responders to SVR by elucidating the relationships among SVR, postoperative ESVI, $\mathrm{EF}$, and survival.

\section{MATERIALS AND METHODS}

We conducted a retrospective multicenter study to investigate the effects of SVR on postoperative ESVI, EF, and survival in those who underwent CABG for ischemic heart disease with LV dysfunction ( $\mathrm{EF} \leq 40 \%$ in any modality). We used data from a dedicated database, the SURgical VentrIcular reconstruction for severe VEntricular dysfunction (SURVIVE) registry database, which was constructed to collect data on patients with heart failure and LV systolic dysfunction who had undergone cardiac surgery in 17 hospitals in Japan since 1999. Among 1701 patients registered, 1385 underwent CABG for ischemic heart disease. Although 414 patients who had complete datasets of preoperative and postoperative $\mathrm{LV}$ volume were candidates, another 121 were excluded considering the bias of LV volume measurement and diversity of surgical procedures. The Bland-Altman analysis was performed to determine the magnitude and directions of intermodality bias for the ESVI and EF using limits of agreement (defined as \pm 1.96 standard deviation from the mean difference) in patients who had data from multiple modalities. ${ }^{9}$ Then, the ESVI and EF of quantitative gated single photon computed emission tomography, left ventriculography, and 2-dimensional echocardiography were compared with magnetic resonance imaging (MRI) as the reference standard, and a considerable bias was found between 2-dimensional echocardiography and other modalities (Figure E1). Then, those with data only from 2-dimensional echocardiography were excluded from the study, and other modalities were selected in the following order for those with multiple modality data: MRI, quantitative gated single photon computed emission tomography, and left ventriculography. Moreover, those with surgical procedures that had been performed for the small number of patients (eg, mitral valve [MV] replacement, chordal cutting, LV linear closure, and SVR without anterior wall incision) were excluded. Finally, the study subjects were 293 patients who underwent CABG for ischemic heart disease between November 1999 and September 2015 (Figure 1), and the complete datasets of the preoperative and postoperative ESVI and EF from the same modality were acquired from MRI, quantitative gated single photon computed emission tomography, and left ventriculography for 49 patients $(17 \%), 35$ patients $(12 \%)$, and 209 patients $(71 \%)$, respectively. Completeness of follow-up was calculated at each time point using a simplified person-time method. ${ }^{10}$ The median follow-up was 6.8 years (interquartile range [IQR], 3.2-9.8 years), and the rates of complete follow-up at 3 years, 5 years, and 10 years were $90 \%, 85 \%$, and $73 \%$, respectively. Mortality was detected on the basis of medical records or follow-up inquiries to the attending cardiologists that were made in each hospital. The study protocol was approved by the institutional review boards of all the participating hospitals, and the requirement for obtaining informed consent was waived. 


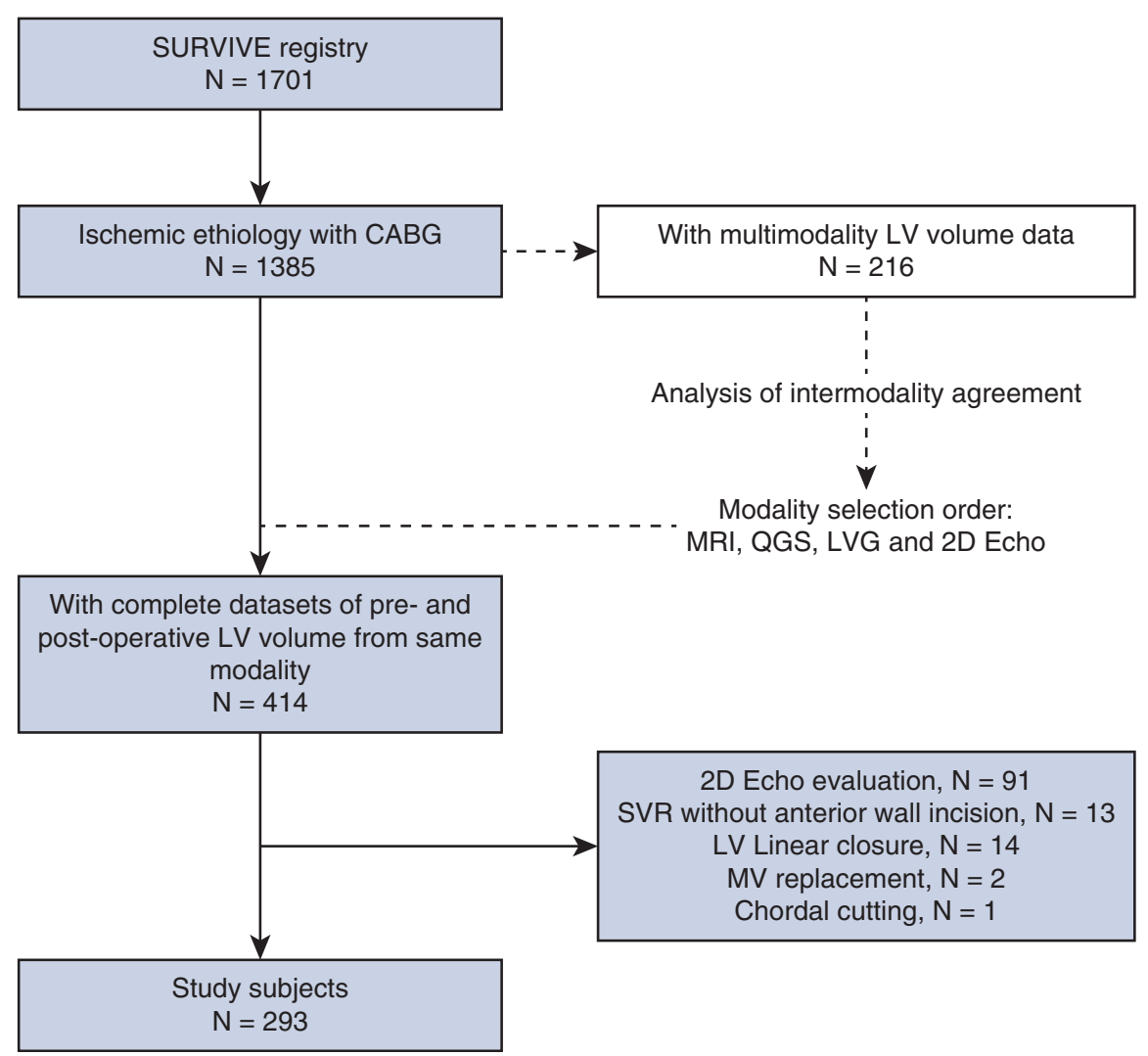

FIGURE 1. CONSORT diagram of recruitment of the study. $C A B G$, Coronary artery bypass grafting; $L V$, Left ventricle; $M R I$, magnetic resonance imaging; $Q G S$, quantitative gated single photon computed emission tomography; $L V G$, left ventriculography; Echo, echocardiography; SVR, surgical ventricular reconstruction; $M V$, mitral valve.

\section{Procedures}

All SVR procedures included in this study had anterior wall incision, and the types of procedure were selected on the basis of the surgeons' preferences. They comprised endoventricular circular patch plasty ${ }^{11}$ for 73 patients $(25 \%)$, septal anterior ventricular exclusion ${ }^{12}$ for 54 patients $(18 \%)$, overlapping left ventriculoplasty ${ }^{13}$ for 21 patients $(7 \%)$, and an endocardial linear infarct exclusion technique ${ }^{14}$ for 17 patients $(6 \%)$. The endoventricular patch was used in the former 2 procedures but not in the latter 2 . MV repair was performed in 100 patients (34\%). Forty-seven patients (16\%) underwent submitral procedures, including papillary muscle approximation in 43 patients $(15 \%)$ and papillary muscle suspension in 18 patients $(6 \%)$ (Video 1). The annuloplasty ring for MV repair was generally downsized but was true-sized for some of those with submitral procedures.

\section{Statistical Analysis}

Continuous variables were expressed as mean \pm standard deviation when normally distributed or medians with IQRs when not normally distributed. All continuous variables were tested for normality using the Shapiro-Wilk test. The categoric variables were expressed as numbers and percentages. Those with missing data for variables used were dropped from each analysis. Student and paired $t$ tests were used for comparisons of normally distributed variables, whereas the Mann-Whitney $U$ test and Wilcoxon signed-rank test were performed for unpaired and paired data without normal distribution, respectively. Categoric variables were compared using the chi-square test or Fisher exact test, as appropriate. The standardized difference (Cohen's d) was calculated for each variable in comparison between those with and without SVR. ${ }^{15}$ Correlations between variables were assessed using Pearson's correlation coefficients (r) when normally distributed or Spearman's rank correlation coefficients $\left(r_{\mathrm{s}}\right)$ when not normally distributed. Survival analysis was performed using the Kaplan-Meier method, wherein those who were lost to follow-up were

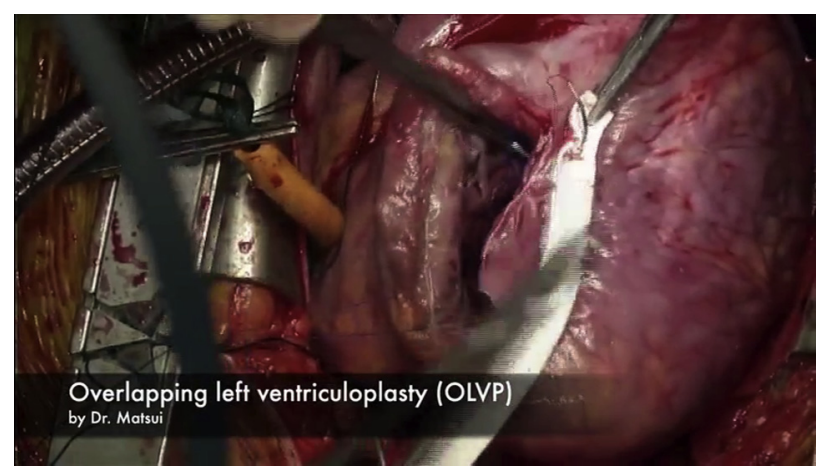

VIDEO 1. Four different SVR and submitral procedures were included in our study: endoventricular circular patch plasty and septal anterior ventricular exclusion by Dr Isomura, papillary muscle approximation and overlapping left ventriculoplasty by Dr Matsui, and endocardial linear infarct exclusion technique by Dr Yaku. Video available at: https://www.jtcvs. org/article/S0022-5223(18)32003-8/fulltext. 
TABLE 1. Baseline characteristics and surgical data of subjects

\begin{tabular}{|c|c|c|c|c|}
\hline Variables & No SVR N = 128 & SVR N $=165$ & $P$ values & Standardized difference (Cohen's d) \\
\hline Age, $y$ & $62(57,70)$ & $64(57,72)$ & .49 & 0.082 \\
\hline Male, $n(\%)$ & $112(88 \%)$ & $143(87 \%)$ & .86 & 0.025 \\
\hline Number of coronary lesions & $3(3,3)$ & $3(2,3)$ & .002 & 0.281 \\
\hline Left main, $\mathrm{n}(\%)$ & $24(19 \%)$ & $21(13 \%)$ & .19 & 0.167 \\
\hline Anterior descending, $\mathrm{n}(\%)^{*}$ & $126(99 \%)$ & $116(95 \%)$ & .06 & 0.252 \\
\hline Circumflex, $\mathrm{n}(\%)^{*}$ & $111(87 \%)$ & $98(81 \%)$ & .22 & 0.177 \\
\hline Right, $\mathrm{n}(\%)^{*}$ & $111(87 \%)$ & $87(71 \%)$ & .002 & 0.407 \\
\hline Atrial fibrillation, $\mathrm{n}(\%)$ & $8(6 \%)$ & $15(9 \%)$ & .39 & 0.105 \\
\hline Diabetes, $\mathrm{n}(\%) \dagger$ & $73(58 \%)$ & $49(49 \%)$ & .18 & 0.189 \\
\hline Dialysis, n (\%) & $4(3 \%)$ & $6(4 \%)$ & 1.0 & 0.028 \\
\hline LV aneurysm, $\mathrm{n}(\%)$ & $47(37 \%)$ & $52(32 \%)$ & .38 & 0.109 \\
\hline$\%$ Viable segments in the LV, $\% \dagger$ & $81(69,94)$ & $69(56,81)$ & .002 & 0.565 \\
\hline $\begin{array}{l}\text { NYHA functional class } \\
\text { I } \\
\text { II } \\
\text { III } \\
\text { IV }\end{array}$ & $\begin{array}{c}3(2 \%) \\
76(59 \%) \\
36(28 \%) \\
13(10 \%)\end{array}$ & $\begin{array}{c}4(2 \%) \\
47(29 \%) \\
80(49 \%) \\
34(21 \%)\end{array}$ & $<.001$ & 0.661 \\
\hline Inotrope use, $\mathrm{n}(\%)$ & $4(3 \%)$ & $13(8 \%)$ & .13 & 0.203 \\
\hline IABP, n (\%) & $8(6 \%)$ & $6(4 \%)$ & .41 & 0.122 \\
\hline PCPS, n ( \% $)$ & 0 & $1(0.6 \%)$ & 1.0 & 0.103 \\
\hline Beta-blocker, n $(\%)^{*}$ & $76(69 \%)$ & $85(52 \%)$ & .004 & 0.355 \\
\hline $\mathrm{LV}$ end-diastolic diameter, $\mathrm{mm} \doteqdot$ & $59 \pm 8$ & $63 \pm 9$ & $<.001$ & 0.436 \\
\hline Preoperative EF, \% & $30(22,36)$ & $26(18,32)$ & $<.001$ & 0.478 \\
\hline Preoperative ESVI, $\mathrm{mL} / \mathrm{m}^{2}$ & $78(56,106)$ & $103(77,141)$ & $<.001$ & 0.649 \\
\hline $\begin{array}{l}\text { MR grade } \ddagger \\
\quad \text { None } \\
1+ \\
2+ \\
3+ \\
4+\end{array}$ & $\begin{array}{c}29(24 \%) \\
51(43 \%) \\
22(18 \%) \\
13(11 \%) \\
5(4 \%)\end{array}$ & $\begin{array}{c}18(11 \%) \\
76(46 \%) \\
45(27 \%) \\
19(12 \%) \\
7(4 \%)\end{array}$ & .05 & 0.381 \\
\hline $\begin{array}{l}\text { Tricuspid regurgitation grade, } \mathrm{n}(\%)^{*} \\
\text { None } \\
1+ \\
2+ \\
3+ \\
4+\end{array}$ & $\begin{array}{c}62(53 \%) \\
44(38 \%) \\
11(9 \%) \\
0 \\
0\end{array}$ & $\begin{array}{c}33(20 \%) \\
105(64 \%) \\
20(12 \%) \\
6(4 \%) \\
0\end{array}$ & $<.001$ & 0.761 \\
\hline $\begin{array}{l}\text { CABG, } \mathrm{n}(\%) \\
\text { Thoracic artery use, n (\%) } \dagger \\
\text { Number of anastomoses }\end{array}$ & $\begin{array}{c}128(100 \%) \\
121(97 \%) \\
4(3,4)\end{array}$ & $\begin{array}{c}165(100 \%) \\
104(92 \%) \\
3(2,3)\end{array}$ & $\begin{array}{c}- \\
.15 \\
<.001\end{array}$ & $\begin{array}{c}- \\
0.202 \\
0.432\end{array}$ \\
\hline $\begin{array}{l}\text { SVR, n }(\%) \\
\text { With patch }\end{array}$ & $\begin{array}{l}0 \\
0\end{array}$ & $\begin{array}{l}165(100 \%) \\
127(77 \%)\end{array}$ & $\begin{array}{l}- \\
-\end{array}$ & - \\
\hline $\begin{array}{l}\text { MV repair, } \mathrm{n}(\%) \\
\text { Ring size, } \mathrm{mm}\end{array}$ & $\begin{array}{l}24(19 \%) \\
26(26,28)\end{array}$ & $\begin{array}{l}76(46 \%) \\
26(26,28)\end{array}$ & $\begin{array}{c}<.001 \\
.35\end{array}$ & $\begin{array}{l}0.596 \\
0.217\end{array}$ \\
\hline Submitral procedure, $\mathrm{n}(\%)_{\ddagger}^{+}$ & $10(8 \%)$ & $37(23 \%)$ & .001 & 0.406 \\
\hline Maze, n (\%) & $1(0.8 \%)$ & $7(4 \%)$ & .14 & 0.212 \\
\hline Tricuspid annuloplasty, n (\%) & $8(6 \%)$ & $16(10 \%)$ & .39 & 0.125 \\
\hline
\end{tabular}


TABLE 1. Continued

\begin{tabular}{lcccr}
\hline \multicolumn{1}{c}{ Variables } & No SVR N $=\mathbf{1 2 8}$ & SVR N $=\mathbf{1 6 5}$ & $\boldsymbol{P}$ values & Standardized difference (Cohen's d) \\
\hline Aortic crossclamp time, $\min \dagger$ & $97(50,141)$ & $96(62,149)$ & .45 & 0.119 \\
Cardiopulmonary bypass time, $\min \dagger$ & $172(126,256)$ & $176(130,234)$ & .90 & 0.018 \\
\hline
\end{tabular}

$S V R$, Surgical ventricular reconstruction; $L V$, left ventricle; $N Y H A$, New York Heart Association; $I A B P$, intra-aortic balloon pump; $P C P S$, percutaneous cardiopulmonary support; $E F$, ejection fraction; $E S V I$, end-systolic volume index; $M R$, mitral regurgitation; $C A B G$, coronary artery bypass grafting; $M V$, mitral valve. $*$ Proportion of those with missing values $3 \%$ to $15 \%$. †Proportion of those with missing values greater than $15 \%$. †Proportion of those with missing values $3 \%$ or less.

censored at the date of their latest follow-up.

We hypothesized that adding SVR to CABG could result in a significant reduction of ESVI and increase of EF; the ESVI reduction and EF increase could provide a survival benefit; therefore, adding SVR to CABG could improve the postoperative survival. However, because it is considered that SVR is not always beneficial regardless of the extent of LV remodeling, ${ }^{16}$ we also hypothesized that the effect of SVR has the upper and lower limits, which could be indicated by the extent of LV remodeling and demarcate the responders to SVR. Therefore, the analyses were performed in the following order. First, the multiple linear regression analysis was performed with the stepwise method $(P<.10)$ to estimate the postoperative ESVI and EF, taking into account the contribution of SVR (Appendix E1). Second, the Cox regression analysis was performed to elucidate the effect of postoperative ESVI and EF on survival, where continuous variables were natural log transformed when not normally distributed (Appendix E2). In this analysis, propensity score was calculated and entered into the multivariable Cox proportional hazards model to reduce the treatment bias, taking into account the observational nature of this study; the probability of receiving SVR for each patient was calculated using multivariable logistic regression analysis (Appendix E3). Variables for all the multivariable analyses were selected considering their confounding and clinical relevance as well as multicollinearity (variance inflation factor $<5.0$ ). Finally, subgroup analysis using Cox proportional hazards models were performed to determine the upper and lower limits in the effect of SVR. All analyses were performed using IBM SPSS Statistics (version 24, IBM Corp, Armonk, NY).

\section{RESULTS \\ Baseline Characteristics and Surgical Data}

Table 1 shows the baseline characteristics and surgical data. The median age was 63 years (IQR, 57-71 years), and 255 patients $(87 \%)$ were men. The preoperative ESVI and EF were $91 \mathrm{~mL} / \mathrm{m}^{2}$ (IQR, 66-128 $\mathrm{mL} / \mathrm{m}^{2}$ ) and $28 \%$ (IQR, 20\%-34\%), respectively; there was a significant correlation between them $\left(\mathrm{r}_{\mathrm{s}}=-0.746, P<.001\right)$ (Figure E2). The percentage of viable segments in the LV myocardium was obtained in 126 patients $(43 \%)$ using MRI (52\%) and scintigraphy (48\%). The median percent viability values were $69 \%$ (IQR, $56 \%-81 \%$ ) and $81 \%$ (IQR, 69\%-94\%) for those with and without SVR, respectively $(P=.002)$. There were weak correlations between the percent viability and preoperative ESVI $\left(\mathrm{r}_{\mathrm{s}}=-0.236\right.$, $P=.008)$ and $\mathrm{EF}\left(\mathrm{r}_{\mathrm{s}}=0.220, P=.013\right)$.

\section{Estimation of Postoperative End-Systolic Volume Index and Ejection Fraction}

The postoperative ESVI and EF were evaluated 15 days (median) after surgery (IQR, 11-20 days), and their values were $64 \mathrm{~mL} / \mathrm{m}^{2}$ in median (IQR, $47-88 \mathrm{~mL} / \mathrm{m}^{2}$ ) and $35 \% \pm 11 \%(P<.001$ compared with the preoperative value for each parameter), respectively. The median ESVI reduction rate (postoperative change divided by preoperative value) was $30 \%$ (IQR, 9\%-43\%) and significantly differed between those with and without SVR (SVR, 37\% reduction from $103 \mathrm{~mL} / \mathrm{m}^{2}$ to $65 \mathrm{~mL} / \mathrm{m}^{2}, P<.001$; no SVR, $16 \%$ reduction from $78 \mathrm{~mL} / \mathrm{m}^{2}$ to $62 \mathrm{~mL} / \mathrm{m}^{2}$, $P<.001 ; P<.001$ for SVR vs no SVR). Those with SVR were also associated with a greater increase of postoperative EF (a difference between preoperative and postoperative values) than those without SVR (SVR, $8 \%$ increase from $26 \%$ to $34 \%, P<.001$; no SVR, $6 \%$ increase from $30 \%$ to $36 \%, P<.001 ; P=.025$ for $\mathrm{SVR}$ vs no SVR).

The stepwise multiple linear regression analysis identified the following variables that estimated the postoperative ESVI and EF: gender, preoperative ESVI, preoperative EF, LV aneurysm, submitral procedure, SVR for postoperative ESVI and preoperative ESVI, preoperative EF, MV repair, and SVR for postoperative EF (Table 2). Then, it was ascertained that the best equations to calculate the estimated values of postoperative ESVI and EF for the final sample size of 290 patients were as given below:

Postoperative ESVI $=34.8+11.2$ (gender) +0.51 (preoperative ESVI) -0.44 (preoperative EF) -6.4 (LV aneurysm) - 10.9 (submitral procedure) - 14.5 (SVR) $\left(\mathrm{r}^{2}=0.58\right)$

Postoperative $\mathrm{EF}=21.4-0.04$ (preoperative ESVI) +0.64 (preoperative EF) - 4.3 (MV repair) + $3.1(\mathrm{SVR})\left(\mathrm{r}^{2}=0.50\right)$

where gender $=1$ if male and 0 if female, and LV aneurysm, submitral procedure, MV repair, and SVR $=1$ if they are associated or performed and 0 if not.

Thus, adding SVR to CABG could result in a significant reduction of ESVI and increase of EF.

\section{Effects of Postoperative End-Systolic Volume Index and Ejection Fraction on Mortality}

Of the 293 patients, $69(24 \%)$ died during the study period $(25 \%$ and $22 \%$ of those with and without SVR, respectively, $P=.58$ ). The Kaplan-Meier analysis demonstrated that the 3-, 5-, and 10-year survivals were $92 \%, 87 \%$, and $70 \%$, respectively. Table 3 summarizes the results of the univariable and multivariable Cox proportional hazards models. The multivariable Cox proportional hazards model demonstrated that only the 
TABLE 2. Results of multivariable linear regression analysis for estimation of postoperative end-systolic volume index and ejection fraction

\begin{tabular}{lccr}
\hline \multicolumn{1}{c}{ Variables } & $\begin{array}{c}\text { Regression } \\
\text { coefficient }\end{array}$ & $\mathbf{9 5 \% \text { CI }}$ & $\boldsymbol{P}$ values \\
\hline Postoperative ESVI & & & \\
Male gender & 11.2 & $3.34,19.2$ & .005 \\
Preoperative ESVI, $\mathrm{mL} / \mathrm{m}^{2}$ & 0.51 & $0.43,0.59$ & $<.001$ \\
Preoperative EF, \% & -0.44 & $-0.84,-0.05$ & .027 \\
LV aneurysm & -6.44 & $-12.4,-0.45$ & .035 \\
Submitral procedure & -10.9 & $-18.6,-3.30$ & .005 \\
SVR & -14.5 & $-20.0,-9.00$ & $<.001$ \\
Postoperative EF & & & \\
Preoperative ESVI, $\mathrm{mL} / \mathrm{m}^{2}$ & -0.04 & $-0.07,-0.01$ & .005 \\
Preoperative EF, \% & 0.64 & $0.50,0.78$ & $<.001$ \\
MV repair & -4.32 & $-6.49,-2.15$ & $<.001$ \\
SVR & 3.11 & $1.09,5.12$ & .003 \\
\hline
\end{tabular}

$C I$, Confidence interval; $E S V I$, end-systolic volume index; $E F$, ejection fraction; $L V$, left ventricle; $S V R$, surgical ventricular reconstruction; $M V$, mitral valve.

postoperative EF was significantly associated with postoperative survival (hazard ratio, $0.925 ; 95 \%$ confidence interval, $0.885-0.968 ; P=.001)$. Figure 2 shows a significant difference in survival times among different postoperative EF values. These results suggested that adding SVR to CABG could provide survival benefit by increasing EF.

\section{Upper and Lower Limits in Effects of Surgical Ventricular Reconstruction}

Because there was a significant correlation between postoperative ESVI and EF $\left(\mathrm{r}_{\mathrm{s}}=-0.778, P<.001\right.$, Figure E2), we performed subgroup analysis to elucidate whether the postoperative ESVI (ie, the extent of LV remodeling) limited the effect of EF on survival. As a result, it was found that postoperative EF was significantly associated with survival in those with ESVI of 40 to $80 \mathrm{~mL} / \mathrm{m}^{2}$ (hazard ratio, 0.932; 95\% confidence interval, 0.894-0.973; $P=.001$ ), although it was not in other subgroups (Figure 3): Postoperative ESVI of $40 \mathrm{~mL} / \mathrm{m}^{2}$ and $80 \mathrm{~mL} / \mathrm{m}^{2}$ could correspond to the lower and upper limits of effective SVR, respectively. Because SVR would reduce ESVI by $14.5 \mathrm{~mL} / \mathrm{m}^{2}$, those who were estimated to have postoperative ESVI within the target range $\left(40-80 \mathrm{~mL} / \mathrm{m}^{2}\right)$ could have a survival benefit from the increase of EF by SVR. The estimated increase of EF by $3.1 \%$ with SVR in those with ESVI of 40 to $80 \mathrm{~mL} / \mathrm{m}^{2}$ would result in approximately $21 \%$ reduction in mortality risk. Thus, estimation of ESVI can help find the responders to SVR. The values dividing each subgroup were determined considering the results of Cox proportional hazards models with various categorizations (Figure E3). The details of the subgroups of postoperative ESVI are shown in Table E1.

\section{DISCUSSION}

We demonstrated that the postoperative EF was significantly associated with survival after CABG with or without SVR, although this association was limited within a specific range of postoperative ESVI. Because SVR could provide a significant reduction of ESVI and increase of EF, adding SVR to CABG could provide a survival benefit by increasing EF for the selected patients regarding postoperative ESVI. Thus, estimating postoperative ESVI could help identify who would benefit from CABG plus SVR compared with CABG alone.

In this study, we found that SVR was one of the variables that were significantly associated with the postoperative ESVI and EF: Adding SVR to CABG could result in a $14.5 \mathrm{~mL} / \mathrm{m}^{2}$ reduction of ESVI and a $3.1 \%$ increase of EF. On the other hand, although the postoperative ESVI $(<60$ $70 \mathrm{~mL} / \mathrm{m}^{2}$ ) could have predicted a higher survival, ${ }^{3,4}$ only the postoperative EF was identified to be significantly associated with the postoperative survival in the multivariable Cox proportional hazards model. Thus, it was suggested that SVR could provide survival benefit not by reducing ESVI but by increasing EF. Moreover, it was also demonstrated that the absolute value of postoperative EF, rather than the extent of postoperative improvement of EF, was the significant variable. Some previous studies focused on myocardial viability, which could be indicated by the extent of postoperative improvement of $\mathrm{EF}$, as an important predictor of survival after CABG for ischemic heart disease, although it remains controversial. ${ }^{17-21}$ Our results suggested that it could be required for better survival to

TABLE 3. Results of Cox proportional hazards models for postoperative survival

\begin{tabular}{|c|c|c|c|c|}
\hline \multirow[b]{2}{*}{ Variables } & \multicolumn{2}{|c|}{ Univariable } & \multicolumn{2}{|c|}{ Multivariable } \\
\hline & HR $(95 \%$ CI $)$ & $P$ values & HR $(95 \%$ CI $)$ & $P$ values \\
\hline Postoperative ESVI (log-transformed) & $1.947(1.170,3.240)$ & .010 & $0.601(0.223,1.615)$ & .31 \\
\hline Postoperative EF & $0.956(0.935,0.978)$ & $<.001$ & $0.925(0.885,0.968)$ & .001 \\
\hline ESVI reduction rate (log-transformed) & $1.829(0.710,4.710)$ & .21 & $1.147(0.340,3.866)$ & .83 \\
\hline EF increase (log-transformed) & $1.050(0.562,1.960)$ & .88 & $2.930(0.989,8.680)$ & .052 \\
\hline SVR & $2.108(1.272,3.494)$ & .004 & $1.731(0.953,3.143)$ & .07 \\
\hline Propensity score & $6.930(2.007,23.93)$ & .002 & $1.221(0.226,6.578)$ & .82 \\
\hline
\end{tabular}

$H R$, Hazard ratio; $C I$, confidence interval; $E S V I$, end-systolic volume index; $E F$, ejection fraction; $S V R$, surgical ventricular reconstruction. 


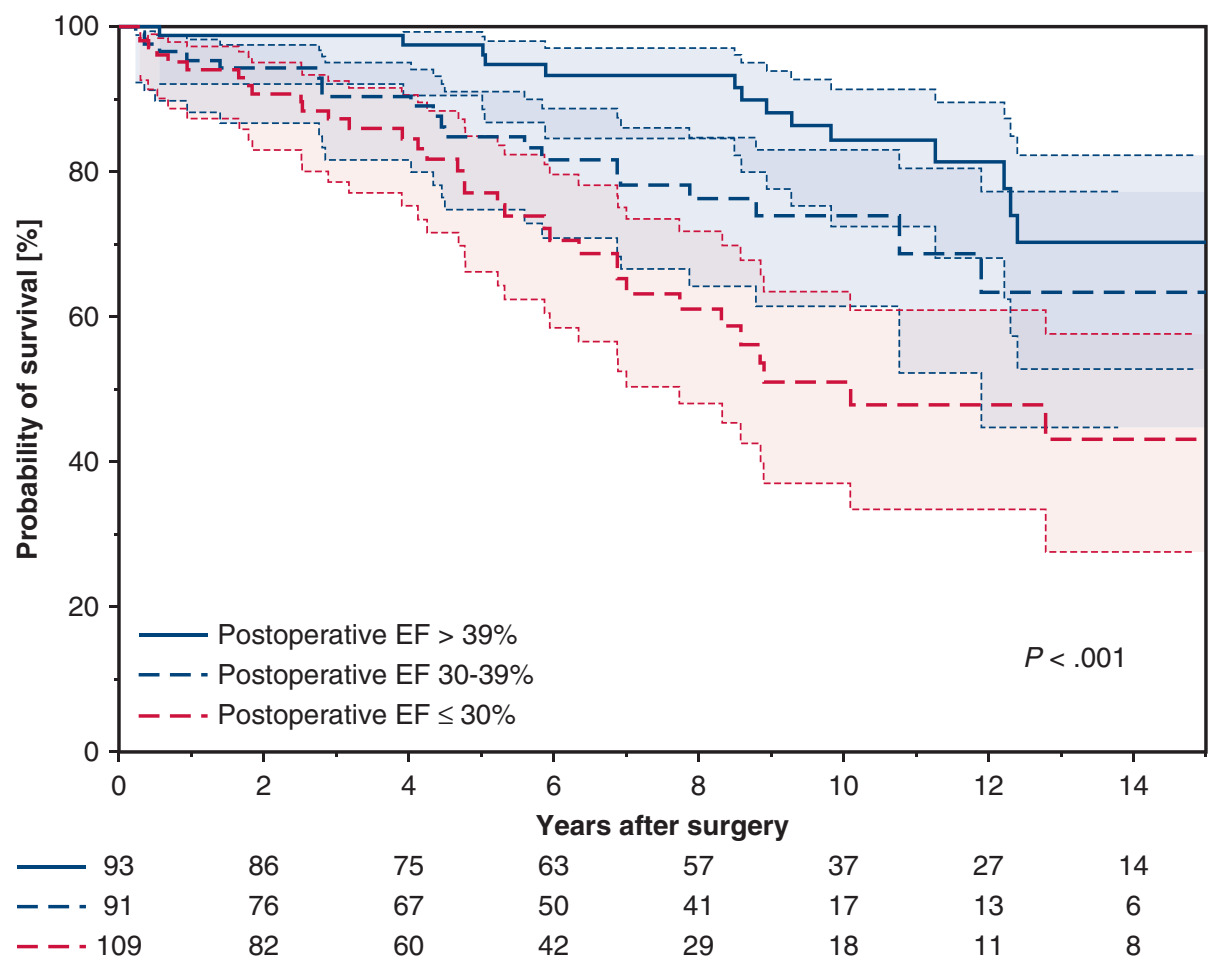

FIGURE 2. Postoperative survival curves for 3 different groups divided according to tertile values of postoperative EF. Shaded areas indicate $95 \%$ confidence intervals. $E F$, Ejection fraction.

keep postoperative EF as high as possible, regardless of the postoperative change of this parameter. Therefore, in consideration of whether SVR should be added or not, the perspective that a higher postoperative EF could be estimated with SVR than without it could encourage surgeons to perform the procedure. On the other hand, it is doubted whether all the patients could have survival benefit from SVR by increasing EF, because it is considered that SVR could not change the fate of the extremely deteriorated LV and would not be required for the LV with sufficient ability. ${ }^{16}$ Thus, it would be natural that the extent of LV remodeling limited the positive effect of EF increase by SVR on survival.
Because the postoperative EF significantly correlated with ESVI, we conducted subgroup analysis dividing the subjects according to the postoperative ESVI (ie, the extent of LV remodeling) and found that the beneficial effect of postoperative $\mathrm{EF}$ was limited to those with postoperative ESVI of 40 to $80 \mathrm{~mL} / \mathrm{m}^{2}$. Because the IQR of preoperative ESVI in this patient group was 79 to $111 \mathrm{~mL} / \mathrm{m}^{2}$, this result was consistent with previous reports that suggested that those with mid-range preoperative ESVI were responders to $\mathrm{SVR}$, with ranges of 80 to $120 \mathrm{~mL} / \mathrm{m}^{2}$ reported by Skelley and colleagues, ${ }^{22} 100$ to $130 \mathrm{~mL} / \mathrm{m}^{2}$ by Yamazaki and colleagues, ${ }^{23}$ and 105 to $150 \mathrm{~mL} / \mathrm{m}^{2}$ by Kainuma and colleagues. ${ }^{24}$ Thus, those who are estimated to have the

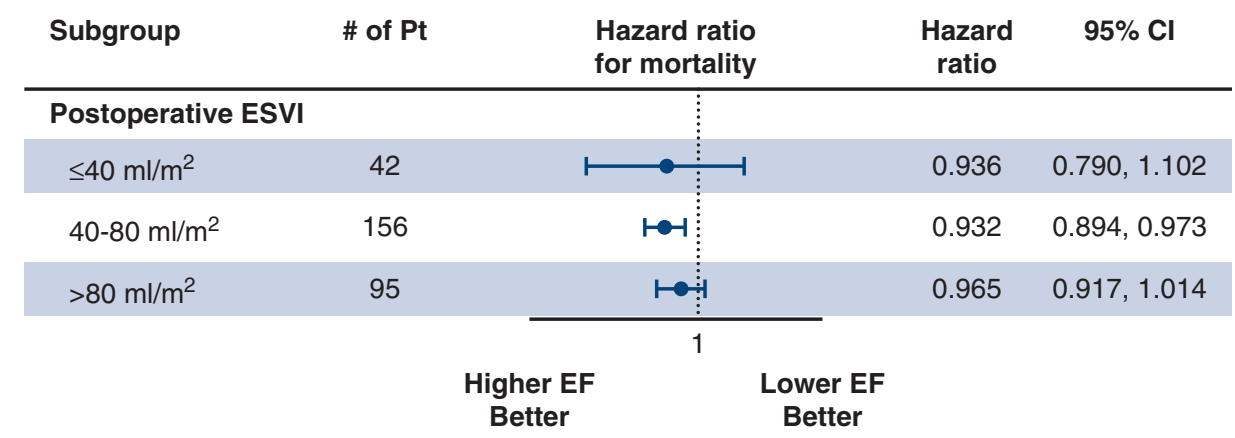

FIGURE 3. Effect of postoperative EF on survival in each subgroup regarding postoperative ESVI. ESVI, End-systolic volume index; $P t$, patient; $C I$, confidence interval; $E F$, ejection fraction. 


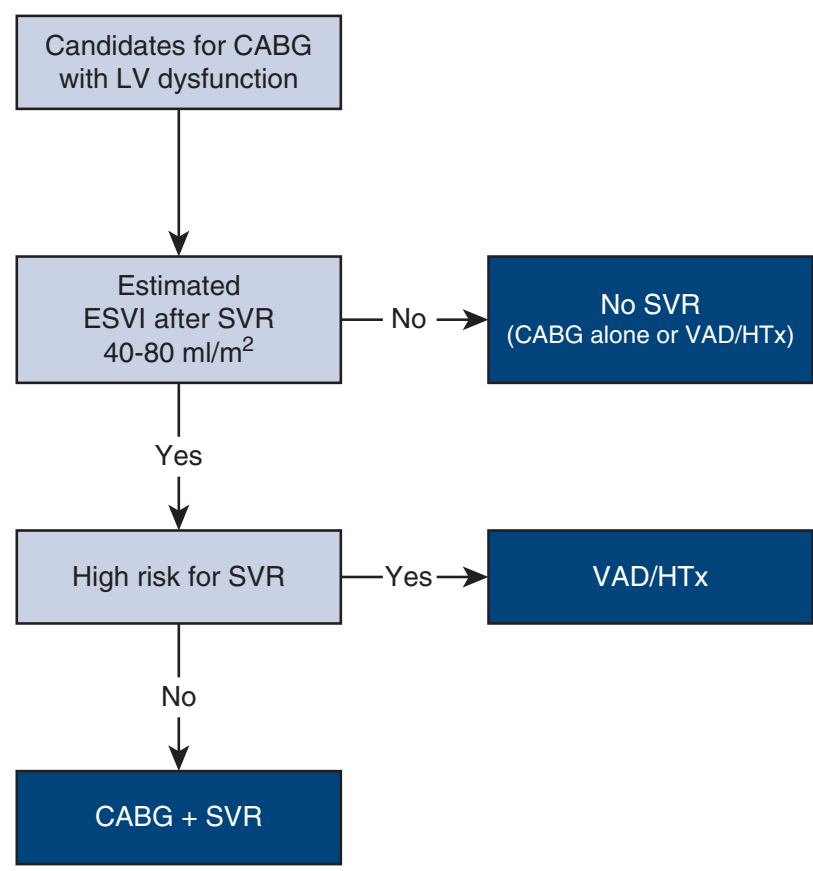

FIGURE 4. Flowchart of the surgical decision pathway to SVR. $C A B G$, Coronary artery bypass grafting; $L V$, left ventricle; $E S V I$, end-systolic volume index; $S V R$, surgical ventricular reconstruction; $V A D$, ventricular assist device; $H T x$, heart transplantation.

postoperative ESVI within the target range of 40 to $80 \mathrm{~mL} /$ $\mathrm{m}^{2}$ could be responders to SVR, because the increase of EF by adding SVR could be beneficial only within this range of ESVI.

On the other hand, it is not simple to identify the responders to SVR, because the postoperative ESVI cannot be estimated by a single effect of SVR. Several factors are involved in the estimation, and the surgical technique is just one of these. Actually, the extent of preoperative LV remodeling (ie, preoperative ESVI and EF) affected ESVI more dominantly. This would be consistent with the previous reports that showed a wide range of perioperative $\mathrm{LV}$ volumes and its reduction rates, ${ }^{22,25-27}$ suggesting that the volume reduction effect of SVR could be affected and the postoperative LV volume could vary depending on the individual condition of each patient. These results also could explain why it is difficult to prove the benefit of SVR by a simple comparison study, such as a randomized controlled trial. ${ }^{1}$

SVR may not be a procedure that provides a survival benefit for all patients who undergo CABG for ischemic heart disease. However, because conventional surgery could be an alternative to transplantation and ventricular assist device therapy for highly selected patients, ${ }^{28}$ SVR could provide a survival benefit if the indication is carefully determined. On the other hand, the purpose of this study was to identify who could benefit from SVR plus CABG compared with $\mathrm{CABG}$ alone, by elucidating the specific effects of SVR on ESVI and EF; this is different from estimating survival time of individual patients if SVR was performed, which we had reported previously. ${ }^{29}$ In surgical decision making, we should take into consideration not only the benefit of adding SVR to CABG but also the mortality risk of the entire surgical procedure: long-term survival could not always be expected even if adding SVR improved survival to some extent. For high-risk patients, ventricular assist device and transplantation should be considered even if the postoperative ESVI could be estimated within the target range for SVR (Figure 4).

\section{Study Limitations}

One of the major limitations of this study was its retrospective design. Selection bias for surgical procedures could have affected our results. Therefore, we calculated the propensity score and entered it into the multivariable model to reduce the bias. Moreover, because the relationship between ESVI and EF was similar between those with and without SVR (Figure E2), we assumed that both LV with or without SVR could be within the same spectrum of LV remodeling, and they could be analyzed as a whole. Second, because our database had a non-negligible amount of missing data for possibly important parameters, such as pulmonary artery pressure, LV diastolic function, and percent viability in the $\mathrm{LV}$, we excluded those parameters from the analyses to defend the sample size, because the analysis, which enrolled the percent viability for less than half of the patients, demonstrated no significant improvement in predictive power of the equations for postoperative ESVI and EF. A prospective study including such parameters with sufficient number of cases will contribute to further clarification by improving the estimation of the postoperative parameters.

\section{CONCLUSIONS}

Adding SVR to CABG could provide a survival benefit by increasing EF for those with postoperative ESVI within a specific range. Thus, the postoperative ESVI could demarcate responders to SVR, and the estimation of this parameter can help identify who would benefit from CABG plus SVR rather than CABG alone. In surgical decision making, however, not only the benefit of adding SVR but also the risk of entire procedure should be taken into consideration.

\section{Conflict of Interest Statement}

Authors have nothing to disclose with regard to commercial support.

The authors thank Hiroaki Iijima for statistical help.

\section{References}

1. Jones RH, Velazquez EJ, Michler RE, Sopko G, Oh JK, O'Connor CM, et al. Coronary bypass surgery with or without surgical ventricular reconstruction. $N$ Engl J Med. 2009;360:1705-17. 
2. White HD, Norris RM, Brown MA, Brandt PW, Whitlock RM, Wild CJ. Left ventricular end-systolic volume as the major determinant of survival after recovery from myocardial infarction. Circulation. 1987;76:44-51.

3. Di Donato M, Castelvecchio S, Menicanti L. End-systolic volume following surgical ventricular reconstruction impacts survival in patients with ischaemic dilated cardiomyopathy. Eur J Heart Fail. 2010;12:375-81.

4. Michler RE, Rouleau JL, Al-Khalidi HR, Bonow RO, Pellikka PA, Pohost GM, et al. Insights from the STICH trial: change in left ventricular size after coronary artery bypass grafting with and without surgical ventricular reconstruction. J Thorac Cardiovasc Surg. 2013;146:1139-45.

5. Isomura T, Hoshino J, Fukada Y, Kitamura A, Katahira S, Kondo T, et al. Volume reduction rate by surgical ventricular restoration determines late outcome in ischaemic cardiomyopathy. Eur J Heart Fail. 2011;13:423-31.

6. Di Donato M, Fantini F, Toso A, Castelvecchio S, Menicanti L, Annest L, et al. Impact of surgical ventricular reconstruction on stroke volume in patients with ischemic cardiomyopathy. J Thorac Cardiovasc Surg. 2010;140:1325-31.

7. Shanmugam G, Ali IS. Surgical ventricular restoration: an operation to reverse remodeling - clinical application (Part II). Curr Cardiol Rev. 2009;5:350-9.

8. Tulner SA, Steendijk P, Klautz RJ, Bax JJ, Schalij MJ, van der Wall EE, et al. Surgical ventricular restoration in patients with ischemic dilated cardiomyopathy: evaluation of systolic and diastolic ventricular function, wall stress, dyssynchrony, and mechanical efficiency by pressure-volume loops. J Thorac Cardiovasc Surg. 2006;132:610-20.

9. Greupner J, Zimmermann E, Grohmann A, Dubel HP, Althoff TF, Borges AC, et al. Head-to-head comparison of left ventricular function assessment with 64-row computed tomography, biplane left cineventriculography, and both 2 and 3-dimensional transthoracic echocardiography: comparison with magnetic resonance imaging as the reference standard. J Am Coll Cardiol. 2012:59: 1897-907

10. Xue X, Agalliu I, Kim MY, Wang T, Lin J, Ghavamian R, et al. New methods for estimating follow-up rates in cohort studies. BMC Med Res Methodol. 2017;17: 155

11. Dor V, Sabatier M, Di Donato M, Montiglio F, Toso A, Maioli M. Efficacy of endoventricular patch plasty in large postinfarction akinetic scar and severe left ventricular dysfunction: comparison with a series of large dyskinetic scars. J Thorac Cardiovasc Surg. 1998;116:50-9.

12. Isomura T, Horii T, Suma H, Buckberg GD, Group R. Septal anterior ventricular exclusion operation (Pacopexy) for ischemic dilated cardiomyopathy: treat form not disease. Eur J Cardiothorac Surg. 2006;29:S245-50.

13. Matsui Y, Fukada Y, Suto Y, Yamauchi H, Luo B, Miyama M, et al. Overlapping cardiac volume reduction operation. J Thorac Cardiovasc Surg. 2002;124:395-7.

14. Yaku H, Ohira S, Yamazaki S, Doi K, Kawajiri H, Morimoto K, et al. Endocardial linear infarct exclusion technique for infarcted lateral wall. Interact Cardiovasc Thorac Surg. 2016;24:460-1.

15. Lenhard W, Lenhard A. Calculation of effect sizes. Available at: https://www psychometrica.de/effect_size.html. Dettelbach, Germany: Psychometrica https://doi.org/1013140/RG2134784245; 2016. Accessed May 10, 2018.

16. Suma H, Anyanwu AC. Current status of surgical ventricular restoration for ischemic cardiomyopathy. Semin Thorac Cardiovasc Surg. 2012;24:294-301.

17. Ragosta M, Beller GA, Watson DD, Kaul S, Gimple LW. Quantitative planar restredistribution $201 \mathrm{Tl}$ imaging in detection of myocardial viability and prediction of improvement in left ventricular function after coronary bypass surgery in patients with severely depressed left ventricular function. Circulation. 1993;87: 1630-41.

18. Senior R, Kaul S, Lahiri A. Myocardial viability on echocardiography predicts long-term survival after revascularization in patients with ischemic congestive heart failure. J Am Coll Cardiol. 1999;33:1848-54.

19. Bax JJ, Schinkel AF, Boersma E, Elhendy A, Rizzello V, Maat A, et al. Extensive left ventricular remodeling does not allow viable myocardium to improve in left ventricular ejection fraction after revascularization and is associated with worse long-term prognosis. Circulation. 2004;110:II18-22.

20. Singh P, Sethi N, Kaur N, Kozman H. Revascularization in severe left ventricular dysfunction: does myocardial viability even matter? Clin Med Insights Cardiol. 2015;9:105-9.

21. Albackr H, Al Mobeirek AF, Al Shamiri M, Albacker TB. Review: do we still need a viability study before considering revascularization in patient with stable coronary artery disease and significant left ventricular systolic dysfunction? Int $J$ Clin Med. 2014:5:242-8.

22. Skelley NW, Allen JG, Arnaoutakis GJ, Weiss ES, Patel ND, Conte JV. The impact of volume reduction on early and long-term outcomes in surgical ventricular restoration for severe heart failure. Ann Thorac Surg. 2011;91:104-11.

23. Yamazaki S, Doi K, Numata S, Itatani K, Kawajiri H, Morimoto K, et al. Ventricular volume and myocardial viability, evaluated using cardiac magnetic resonance imaging, affect long-term results after surgical ventricular reconstruction. Eur J Cardiothorac Surg. 2016;50:704-12.

24. Kainuma S, Taniguchi K, Toda K, Funatsu T, Miyagawa S, Kondoh H, et al Restrictive mitral annuloplasty with or without surgical ventricular reconstruction in ischaemic cardiomyopathy: impacts on neurohormonal activation, reverse left ventricular remodelling and survival. Eur J Heart Fail. 2014;16: 189-200.

25. Yamaguchi A, Adachi H, Kawahito K, Murata S, Ino T. Left ventricular reconstruction benefits patients with dilated ischemic cardiomyopathy. Ann Thorac Surg. 2005;79:456-61.

26. Witkowski TG, ten Brinke EA, Delgado V, Ng AC, Bertini M, Marsan NA, et al Surgical ventricular restoration for patients with ischemic heart failure: determinants of two-year survival. Ann Thorac Surg. 2011;91:491-8.

27. Oh JK, Velazquez EJ, Menicanti L, Pohost GM, Bonow RO, Lin G, et al. Influence of baseline left ventricular function on the clinical outcome of surgical ven tricular reconstruction in patients with ischaemic cardiomyopathy. Eur Heart J. 2013;34:39-47.

28. Kawajiri H, Manlhiot C, Ross H, Delgado D, Billia F, McDonald M, et al High-risk cardiac surgery as an alternative to transplant or mechanical support in patients with end-stage heart failure. J Thorac Cardiovasc Surg. 2017:154:517-25.

29. Wakasa S, Matsui Y, Isomura T, Takanashi S, Yamaguchi A, Komiya T, et al. Risk scores for predicting mortality after surgical ventricular reconstruction for ischemic cardiomyopathy: results of a Japanese multicenter study. J Thorac Car diovasc Surg. 2014;147:1868-74.

Key Words: surgical ventricular reconstruction, ischemic cardiomyopathy, coronary artery bypass grafting, responder 


\section{APPENDIX E1}

Postoperative ESVI and EF were estimated using stepwise multiple linear regression analysis based on the following clinically relevant variables without missing values: age, gender, NYHA functional class, inotrope use, preoperative ESVI, preoperative EF, LV aneurysm, number of anastomoses in CABG, MV repair, submitral procedure, and SVR.

\section{APPENDIX E2}

The multivariable Cox proportional hazards model for postoperative survival was constructed to elucidate whether the postoperative ESVI and EF would estimate survival. The following variables were selected considering the results of previous studies and the bias for receiving SVR (inclusive of variables with proportion of missing values $\leq 3 \%$ ): SVR, propensity score, postoperative ESVI, postoperative EF, ESVI reduction rate, and increase of EF.

\section{APPENDIX E3}

The propensity score was calculated using multivariable logistic regression analysis with the following variables considering their clinical relevance and standardized differences $(>0.1)$, inclusive of variables with proportion of missing values $3 \%$ or less: age, gender, number of coronary lesions, left main disease, atrial fibrillation, LV aneurysm, preoperative NYHA functional class, inotrope use, preoperative mitral regurgitation grade, preoperative LV enddiastolic diameter, preoperative ESVI, and preoperative EF. 

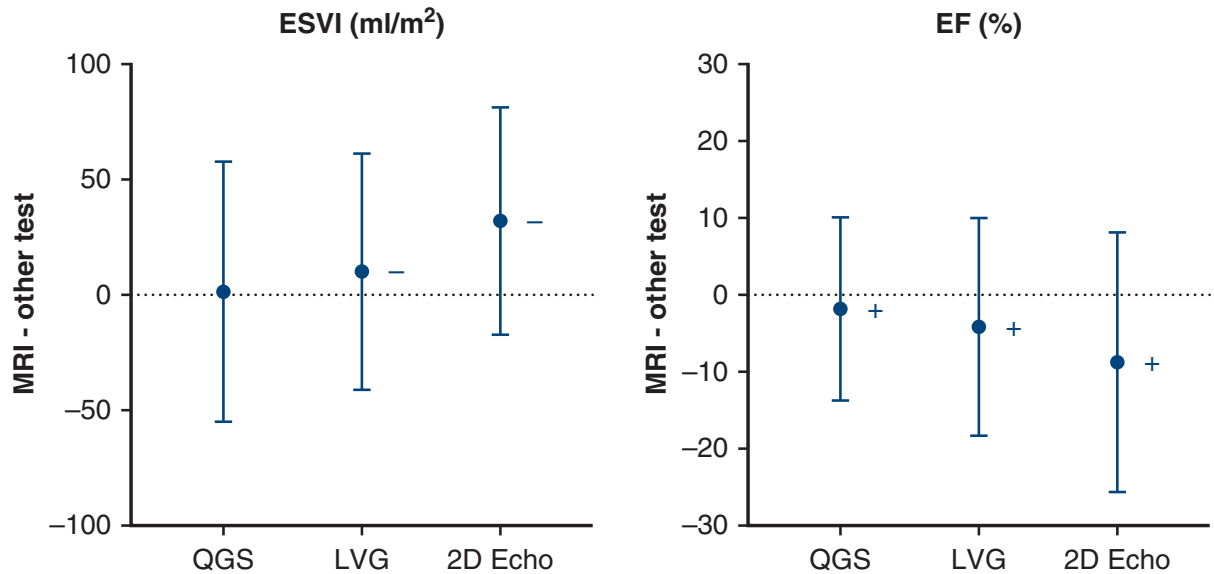

FIGURE E1. Summary of the Bland-Altman analysis of intermodality agreement for ESVI and EF. ESVI, End-systolic volume index; MRI, magnetic resonance imaging; $Q G S$, quantitative gated single photon computed emission tomography; $L V G$, left ventriculography; Echo, echocardiography; -, $P<.05$ underestimation versus MRI; $E F$, ejection fraction;,$+ P<.05$ overestimation versus MRI.
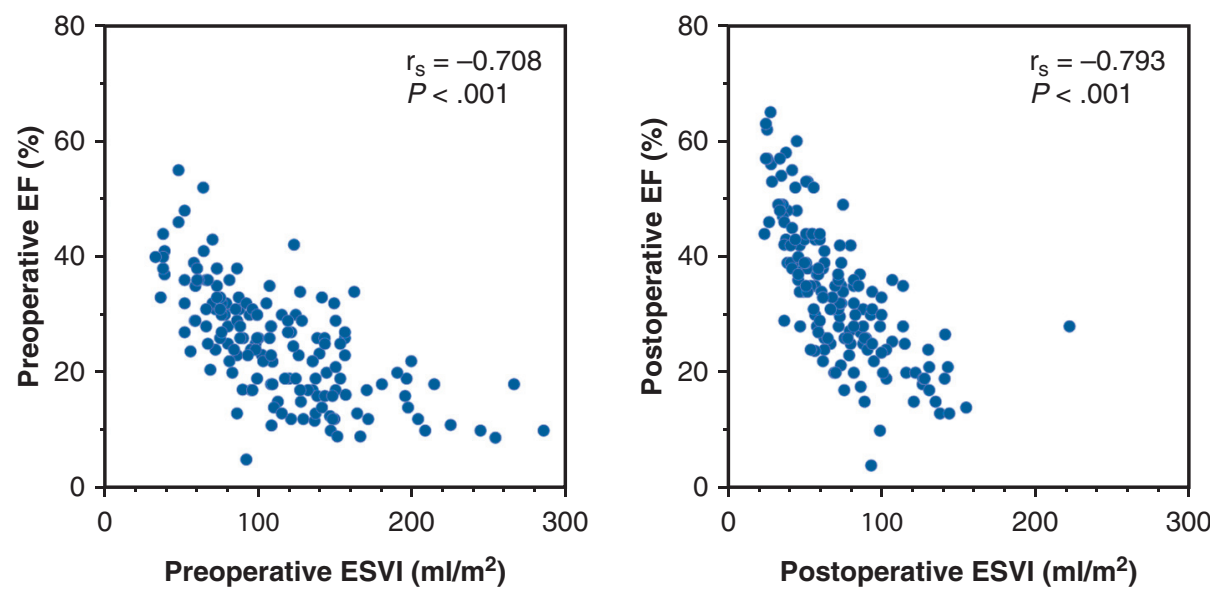

A
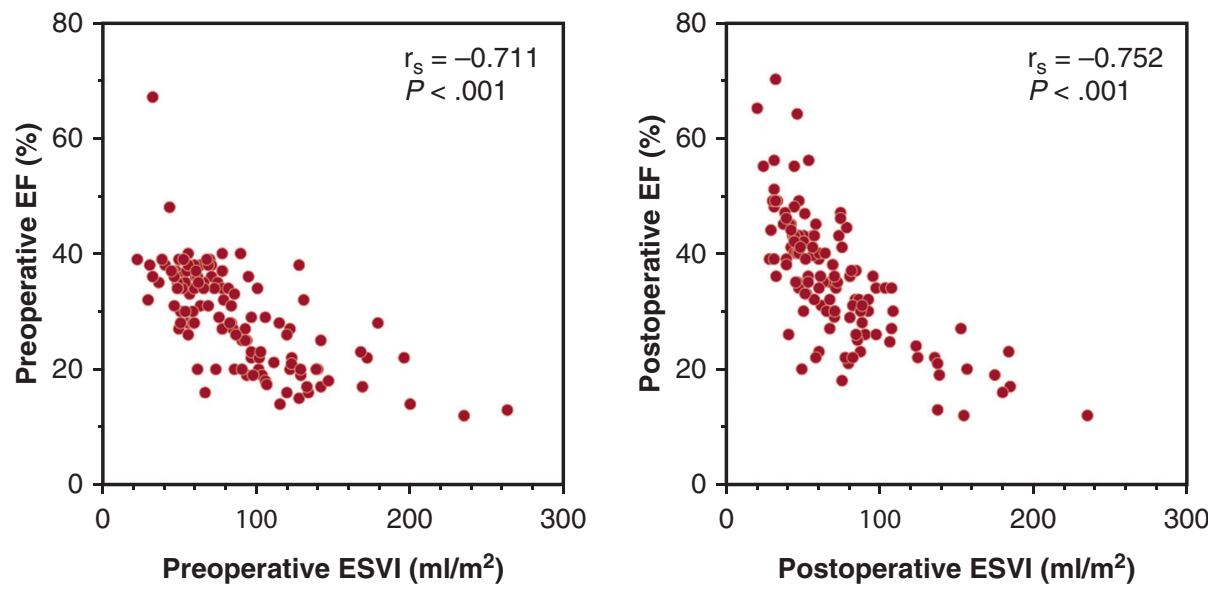

B

FIGURE E2. Correlation between preoperative and postoperative ESVI and EF for those with (A) and without (B) SVR. ESVI, End-systolic volume index; $r_{s}$, Spearman's rank correlation coefficient; $E F$, ejection fraction. 


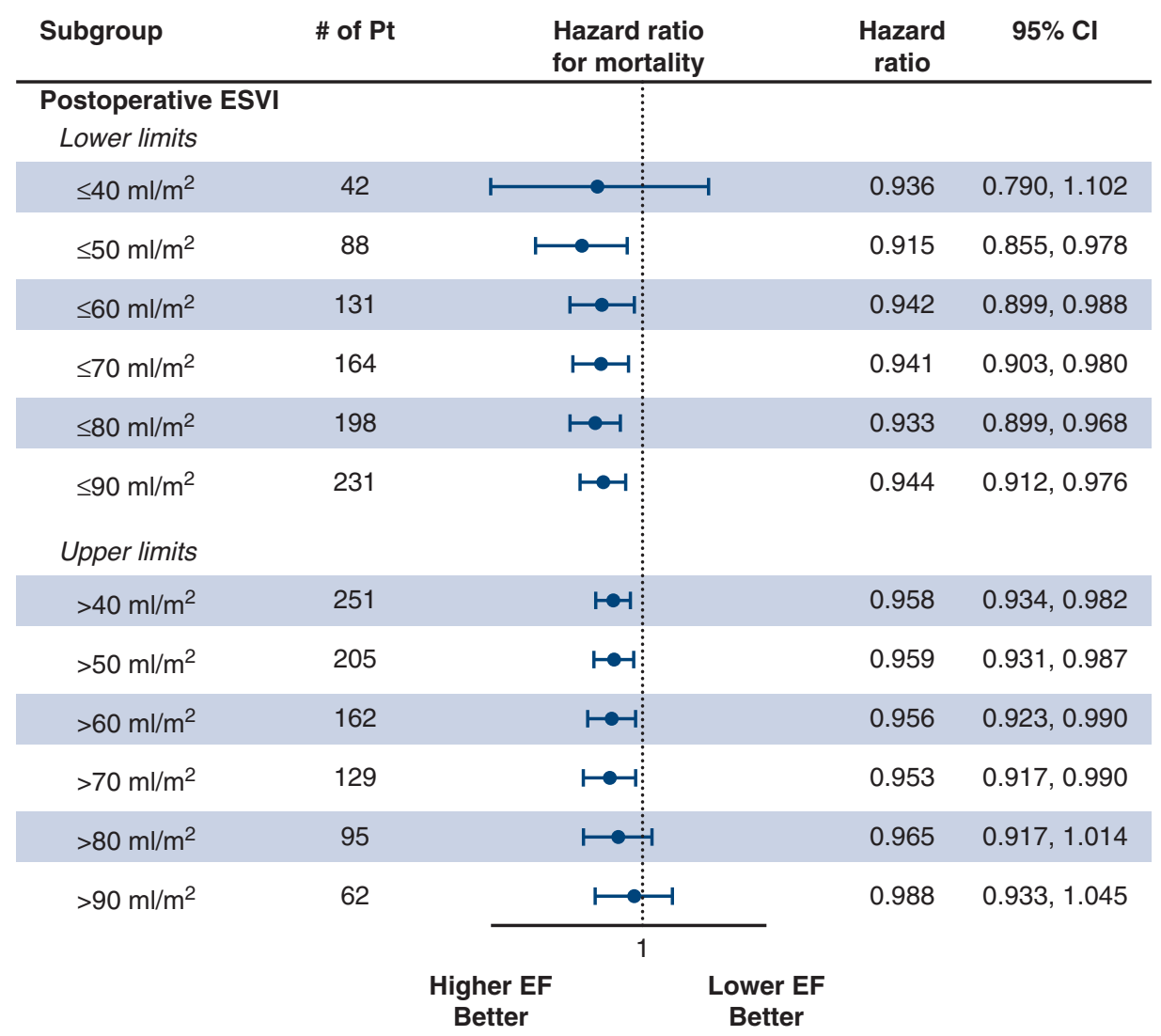

FIGURE E3. Results of subgroup analyses for effect of postoperative EF on survival using various categorizations according to postoperative ESVI. Pt, Patient; $C I$, confidence interval; ESVI, end-systolic volume index; $E F$, ejection fraction.

TABLE E1. Perioperative parameters of patients in each subgroup of postoperative end-systolic volume index

\begin{tabular}{|c|c|c|c|c|c|c|}
\hline & \multicolumn{2}{|c|}{$\begin{array}{c}\text { Postoperative } \\
\text { ESVI } \leq \mathbf{4 0} \mathrm{mL} / \mathrm{m}^{2} \mathrm{~N}=42\end{array}$} & \multicolumn{2}{|c|}{$\begin{array}{c}\text { Postoperative } \\
\text { ESVI } 40-80 \mathrm{~mL} / \mathrm{m}^{2} \mathrm{~N}=156\end{array}$} & \multicolumn{2}{|c|}{$\begin{array}{c}\text { Postoperative } \\
\text { ESVI }>80 \mathrm{~mL} / \mathrm{m}^{2} \mathrm{~N}=95\end{array}$} \\
\hline & No SVR N = 18 & SVR N $=24$ & $\overline{\text { No SVR N }=69}$ & SVR N $=87$ & No SVR N = 41 & SVR N $=54$ \\
\hline Age, y & $68(57,76)$ & $68(60,75)$ & $62(58,70)$ & $66(55,72)$ & $62(56,67)$ & $63(57,69)$ \\
\hline Male, $n(\%)$ & $13(72 \%)$ & $21(88 \%)$ & $60(87 \%)$ & $74(85 \%)$ & $39(95 \%)$ & $48(89 \%)$ \\
\hline Inotrope use, n (\%) & $1(6 \%)$ & $1(4 \%)$ & $1(1 \%)$ & $3(3 \%)$ & $2(5 \%)$ & $9(17 \%)$ \\
\hline NYHA class & $2(2,3)$ & $3(2,3)$ & $2(2,3)$ & $3(2,3)$ & $2(2,3)$ & $3(3,4)$ \\
\hline MR grade & $1(0,1.5)$ & $1(0,1)$ & $1(0,2)$ & $1(1,2)$ & $1(1,2)$ & $2(1,3)$ \\
\hline MV repair, n (\%) & $2(11 \%)$ & $5(21 \%)$ & $11(16 \%)$ & $36(41 \%)$ & $11(27 \%)$ & $35(65 \%)$ \\
\hline Preoperative EF, \% & $33(31,38)$ & $37(32,40)$ & $34(28,37)$ & $26(20,31)$ & $22(17,28)$ & $19(13,25)$ \\
\hline Postoperative EF, \% & $48 \pm 9$ & $50 \pm 8$ & $38 \pm 8$ & $35 \pm 9$ & $26 \pm 7$ & $24 \pm 7$ \\
\hline EF change, $\%$ & $13(10,15)$ & $13(7,20)$ & $6(3,10)$ & $10(3,14)$ & $3(-0.5,7)$ & $5(1,10)$ \\
\hline Preoperative ESVI, $\mathrm{mL} / \mathrm{m}^{2}$ & $54(45,67)$ & $64(42,74)$ & $67(53,85)$ & $96(79,111)$ & $122(93,142)$ & $146(127,168)$ \\
\hline Postoperative ESVI, $\mathrm{mL} / \mathrm{m}^{2}$ & $33(31,38)$ & $34(27,37)$ & $57(48,68)$ & $59(50,70)$ & $98(86,138)$ & $100(89,127)$ \\
\hline ESVI reduction rate, $\%$ & $40(21,56)$ & $45(34,55)$ & $15(-5,28)$ & $39(27,50)$ & $6(-11,27)$ & $29(13,42)$ \\
\hline
\end{tabular}

$E S V I$, End-systolic volume index; $S V R$, surgical ventricular reconstruction; $N Y H A$, New York Heart Association; $M R$, mitral regurgitation; $M V$, mitral valve; $E F$, ejection fraction. 